\title{
Formation of flash-concept for a resource-saving articulated hopper car to transport hot pellets and agglomerate
}

\author{
Oleksij Fomin ${ }^{1}$, Glib Vatulia ${ }^{2}$, and Alyona Lovska ${ }^{3, *}$ \\ ${ }^{1}$ State University of Infrastructure and Technologies, Department of Cars and Carriage Facilities, 9 Kyrylivska Str., Kyiv, 04071, \\ Ukraine \\ ${ }^{2}$ Ukrainian State University of Railway Transport, Department of Structural Mechanics and Hydraulics, 7 Feuerbach Sq., Kharkov, \\ 61050, Ukraine \\ ${ }^{3}$ Ukrainian State University of Railway Transport, Department of wagons, 7 Feuerbach Sq., Kharkov, 61050, Ukraine
}

\begin{abstract}
Higher operational efficiency of hopper cars can be achieved with the flash-concept for a resourcesaving structure. The characteristic feature such cars is the use of circular pipes as the carrying body elements. The engineering solution made it possible to decrease the tare weight of a hopper car in comparison with that of a prototype by 5\%. A 20-9749 hopper car, manufactured by Panutinskiy Car Repair Plant (Ukraine), was taken as a prototype. On the basis of the suggested hopper car, an articulated car was designed. The dynamic loading of the articulated hopper car was defined with mathematical modelling. The study was conducted in plane coordinates. The acceleration values obtained were considered in the strength calculation for the carrying structure of the hopper car. The strength factors were defined in COSMOSWorks software environment. It was determined that the maximum equivalent stresses in elements of the carrying structure did not exceed the admissible values. The results of the research will promote designing innovative hopper cars for transporting hot pellets and agglomerate, thus enhancing higher efficiency of rail transportation.
\end{abstract}

\section{Introduction}

An intense competitive environment in the transport industry requires designing innovative rail transport facilities to maintain a leading position for rail transportation. And particular attention should be given to the carrying structural elements of cars as they constitute a greater part of the tare weight.

Thus, hopper cars have found a wide application for transporting hot pellets and agglomerate at production enterprises. A characteristic of these cars is their sheath which is not welded to the body frame, but hangs on it; the front walls are inclined, which allows the discharge by means of gravity [1]. The carrying structure of a railcar transporting pellets is under constant working and temperature loads from the cargo. Therefore, there is a need to improve the existing structure of a hopper car to provide an appropriate strength and improve the operational efficiency.

\section{Analysis of recent researches}

Improvements in the carrying structure of a 19-9862 hopper car for ensuring the required strength under working loads are described in [2]. The study puts forward some ideas about how to strengthen the assembly unit which connects the end vertical and middle inclined posts with a lateral angle bar of the inclined end wall of a hopper car. The strength calculation is made in DSMFem software package. The results of the calculation confirm the efficiency of the solutions proposed.

A longer service life of hopper railcars is substantiated in [3]. The study gives a general overhaul schedule which provides for a longer service life of railcars. The research is made by an example of a 19-6930 hopper car.

However, the authors do not consider improvements in the carrying structure of a hopper cars used for transporting hot pellets and agglomerate.

The innovation structure of a hopper car developed by the Greenbrier Companies is featured in [4]. The body cubic capacity of the car is $146 \mathrm{~m}^{3}$. The car body can automatically be discharged in 30 seconds. Besides, the speed of unloading commodities can be regulated.

However, the company has not considered problems of designing hopper cars for transporting hot pellets and agglomerate.

Some design features of prospective freight car structures are presented in [5]. The study gives requirements for designing the carrying structures of railcar at the modern stage of rail industry development. But the author does not consider improvements in the carrying structure of a hopper car and ways to increase the operational efficiency.

Development of prospective structures of freight cars is highlighted in $[6,7]$. The studies give spatial models of carrying structures of railcars and their strength calculations.

\footnotetext{
* Corresponding author: alyonaLovskaya.vagons@gmail.com
} 
However, designing resource-saving structures of hopper cars for transporting hot pellets and agglomerate is not covered in the research.

The designing of a freight car body of composite panels is given in [8]. The authors suggest the use of anticorrosive materials for paint-and-lacquer coating of a car. But modernization of hopper cars for transporting hot pellets is not considered in the study.

The purpose of the article. The purpose of the article is to highlight the flash-concept formation for a recoursesaving articulated hopper car for transporting hot pellets and agglomerate.

\section{Results and discussion}

A prospective area in achieving the purpose of the study is creation of the functional-adaptive flash-concept of a railcar by the results of adequate mathematical and computer modelling.

The flash-concept is understood as the technical image of a prospective railcar, intended for theoretical and structural representation of the operational principles.

The authors suggest the use of circular pipes as carrying elements to decrease the tare weight of a hopper car for transporting hot pellets and agglomerate. This engineering solution makes it possible to decrease the tare weight of a hopper car in comparison with that of a prototype (Model 20-9749) by 5\%.

On the basis of the designed structure of a hopper car, an articulated railcar was developed (Fig. 1, 2). The solution may increase the operational efficiency of the car and decrease the production costs in comparison with that of a four-axle car.

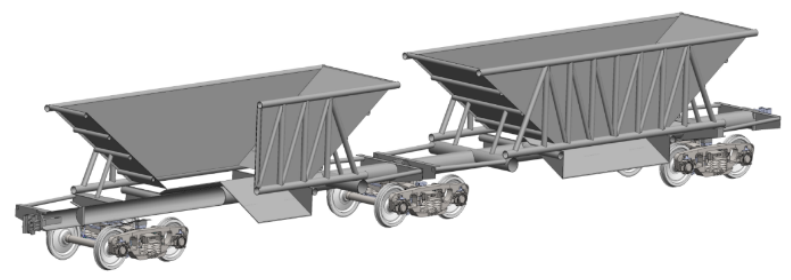

Fig. 1. An articulated hopper car for transporting hot pellets and agglomerate

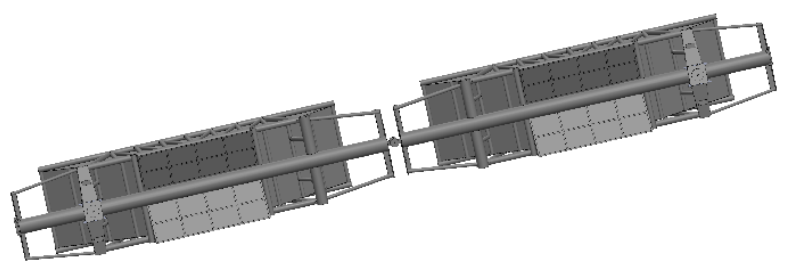

Fig. 2. An articulated hopper car for transporting hot pellets and agglomerate (bottom view).

It should be mentioned that there are articulated hopper cars manufactured by Research and Production Corporation "United Wagon Company" (RPC UWC) (Fig. 3 [9]). However, the company has not designed articulated hopper cars for transporting hot pellets and agglomerate.
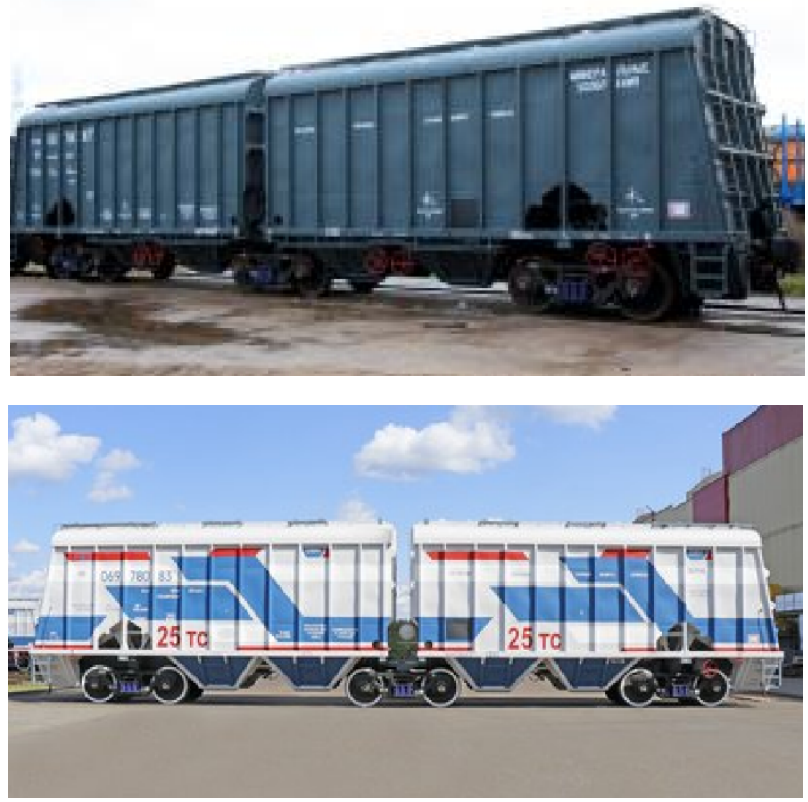

Fig. 3. An articulated hopper car.

While developing the flash-concept of an articulated hopper car, the authors replaced the bolster beam, where it rested on the middle running gear, for a circular section beam (Fig. 4).
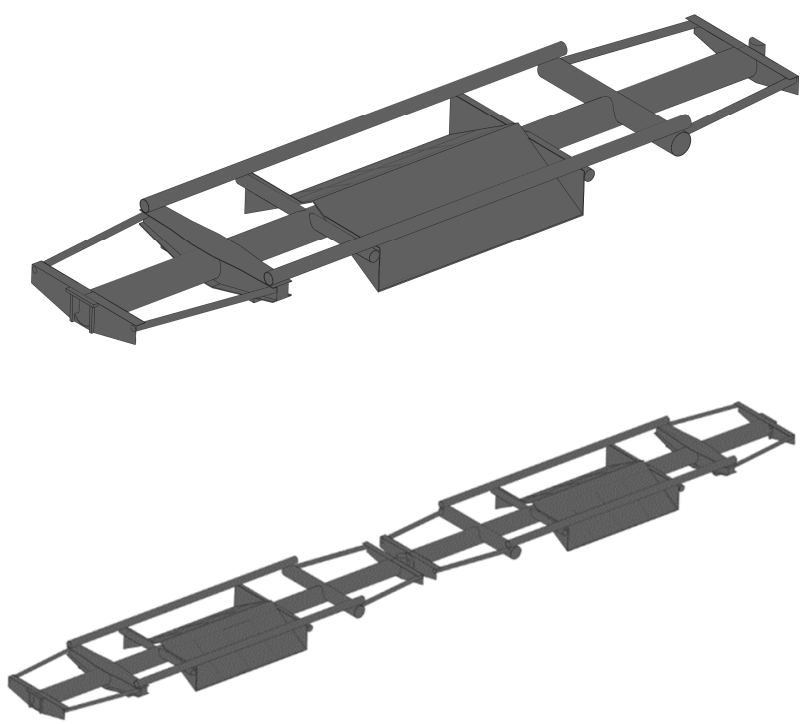

Fig. 4. The frame of an articulated hopper car.

The dynamic loading on the carrying structure of a hopper car at the least favorable operational mode (jerk) was defined with a mathematical model, it was designed by prof. Bogomaz for a long-base flat wagon loaded with tank containers. The model was improved by the authors of the article and considered displacements of two interacting sections of the articulated hopper car.

$$
M_{C_{1}}^{\prime} \cdot \ddot{x}_{C_{1}}+M_{C_{1}} \cdot h \cdot \ddot{\varphi}_{C_{1}}+k^{\prime}\left(x_{C_{1}}-x_{C_{2}}\right)=P_{l},
$$




$$
\begin{aligned}
& I_{C_{1}} \cdot \ddot{\varphi}_{C_{1}}+M_{C_{1}} \cdot h \cdot \ddot{x}_{C_{1}}-g \cdot \varphi_{C_{1}} \cdot M_{C_{1}} \cdot h= \\
& =l \cdot F_{F R}\left(\operatorname{sign} \dot{\Delta}^{G_{1}}-\operatorname{sign} \dot{\Delta}_{2}^{c_{1}}\right)+ \\
& +l\left(k_{1} \cdot \dot{4}^{c_{1}}-k_{2} \cdot \dot{\Delta}_{2}^{c_{1}}\right), \\
& M_{C_{1}} \cdot \ddot{z}_{C_{1}}=k_{1} \cdot \Delta_{1}^{C_{1}}+k_{2} \cdot \Delta_{2}^{c_{1}}-F_{F R}\left(\operatorname{sign} \dot{\Delta}_{1}^{C_{1}}-\operatorname{sign} \dot{\Delta}_{2}^{C_{1}}\right), \\
& M_{C_{2}}^{\prime} \cdot \ddot{x}_{C_{2}}+M_{C_{2}} \cdot h \cdot \ddot{\varphi}_{C_{2}}-k^{\prime}\left(x_{C_{1}}-x_{C_{2}}\right)=0, \\
& I_{C_{2}} \cdot \ddot{\varphi}_{C_{2}}+M_{C_{2}} \cdot h \cdot \ddot{x}_{C_{2}}-g \cdot \varphi_{C_{2}} \cdot M_{C_{2}} \cdot h= \\
& =l \cdot F_{F R}\left(\operatorname{sign} \dot{\Delta}^{c_{2}}-\operatorname{sign} \dot{\Delta}_{2}^{c_{2}}\right)+l\left(k_{1} \cdot \dot{\Delta}^{c_{2}}-k_{2} \cdot \dot{\Delta}_{2}^{c_{2}}\right), \\
& M_{C_{2}} \cdot \ddot{z}_{C_{2}}=k_{1} \cdot \Delta_{1}^{C_{2}}+k_{2} \cdot \Delta_{2}^{C_{2}}-F_{F R}\left(\operatorname{sign} \dot{\Delta}_{1}^{C_{2}}-\operatorname{sign} \dot{\Delta}_{2}^{C_{2}}\right) \text {, }
\end{aligned}
$$

where

$$
\Delta_{1}^{i}=z_{C_{i}}-l \cdot \varphi_{C_{i}} ; \Delta_{2}^{i}=z_{C_{i}}+l \cdot \varphi_{C_{i}}
$$

$M_{C_{i}}^{\prime}$ - the gross weight of the $i$-th section; $M_{C_{i}}$ - the mass of the carrying structure of the $i$-th section; $I_{C_{i}}$ - the inertia moment of the $i$-th section; $P_{l}-$ the value of longitudinal force on the automatic coupling; $F_{F R}$ - the absolute value of dry friction in a spring group; $k^{\prime}-$ the linkage rigidity between sections; $k_{1}, k_{2}$ - the spring rigidity of bogies' spring groups; $x_{i}, \varphi_{i}, z_{i}$ - the coordinates indicating displacements of car sections relative to the corresponding axes.

Besides, jerking (1), (4), bouncing (2), (5) and galloping (3), (6) oscillations were taken into account. The design diagram is given in Fig. 5.

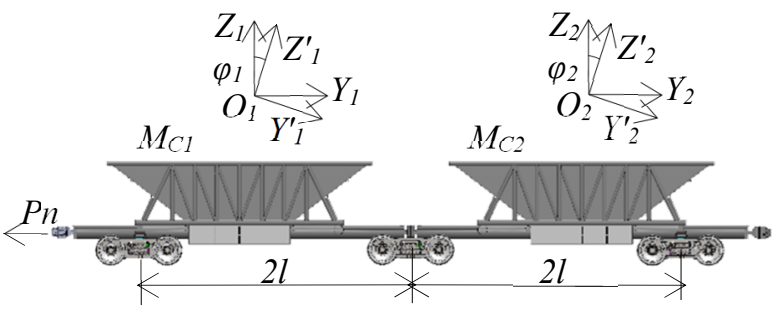

Fig. 5. The design diagram of an articulated hopper car.

The articulator was designed by means of elastic linkage. The value of longitudinal force on the front support of the automatic coupling of a car section was 2.5 MN [10,11]. It was also considered that the car rested on three 18-100 bogies.

As the axial load of wheelsets of this bogie was $23.5 \mathrm{t} / \mathrm{axle}(230.535 \mathrm{kN} / \mathrm{axle})$, the gross weight of the car should not exceed 1,383.21 kN. It should be mentioned that bogies of increased axial loads can be used under the car.

The differential equations were solved in MathCad software suite $[12,13]$. The initial displacements and speeds were taken equal to zero [14-16].

It was established that maximum acceleration on a first section (from the side where the longitudinal force was applied) accounted for $31.4 \mathrm{~m} / \mathrm{sec}^{2}$, and on a second section $-32.3 \mathrm{~m} / \mathrm{sec}^{2}$.

The acceleration values obtained were considered in the strength calculation for the carrying structure of a hopper car as constituents of the dynamic loading.

The strength calculation was made by the finite element method [17-20] in COSMOSWorks software suite.

The authors of the article developed a design diagram of the carrying structure of a hopper car (Fig. 6, 7). It allowed for the vertical static load $P_{v}^{s t}$, the lateral pressure $P_{p}$ on the body walls, and also the longitudinal load $P_{l}$ on the front support of an automatic coupling.

The model was fixed in the areas where it rested on the running gears. The basic carrying elements of the car body were made of Steel grade 09G2S. The movable car lining of higher resistance properties could compensate a heat expansion.

Isoparametric tetrahedrons were used in designing the finite-element model [21-24].

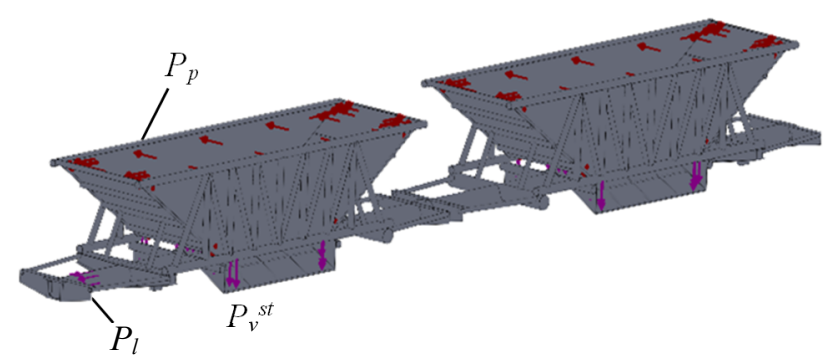

Fig. 6. The design diagram of the carrying structure of a hopper car.

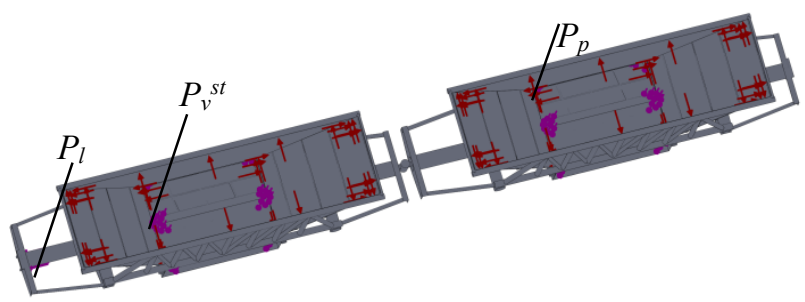

Fig. 7. The design diagram of the carrying structure of a hopper car (bottom view).

The basic characteristics of the finite element model are given in Table 1.

Table 1. The basic characteristics of the finite-element model of the carrying structure of an articulated hopper car

\begin{tabular}{|l|c|}
\hline \multicolumn{1}{|c|}{ Parameter } & Value \\
\hline The number of Jacobian points & 4 \\
\hline The number of units & 1590958 \\
\hline The number of elements & 4845516 \\
\hline The maximum size of an element, mm & 20 \\
\hline The minimum size of an element, $\mathrm{mm}$ & 4 \\
\hline The minimum number of elements in the circle & 10 \\
\hline Ratio of an element size expansion & 1.8 \\
\hline The maximum side ratio & 773.8 \\
\hline Percent of elements with the side ratio less than 3 & 73.6 \\
\hline Percent of elements with the side ratio more than 10 & 3.36 \\
\hline
\end{tabular}


The results of the calculations are given below (Fig. 8 $-14)$.

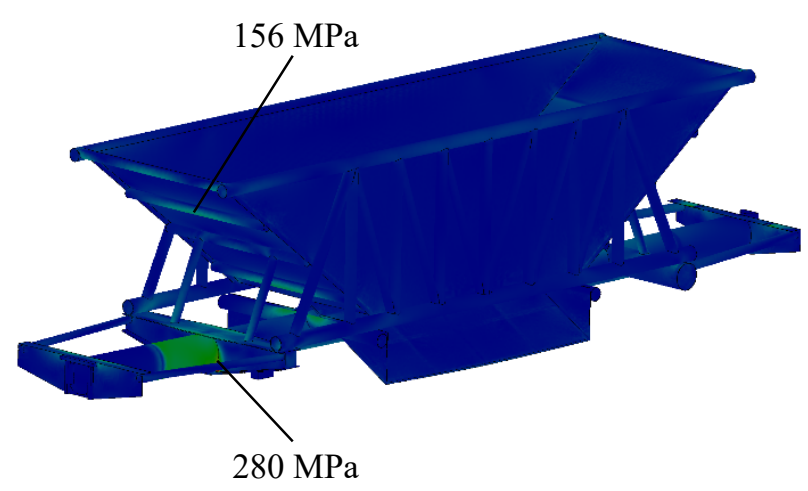

Fig. 8. The stressed state of the section of an articulated hopper car.

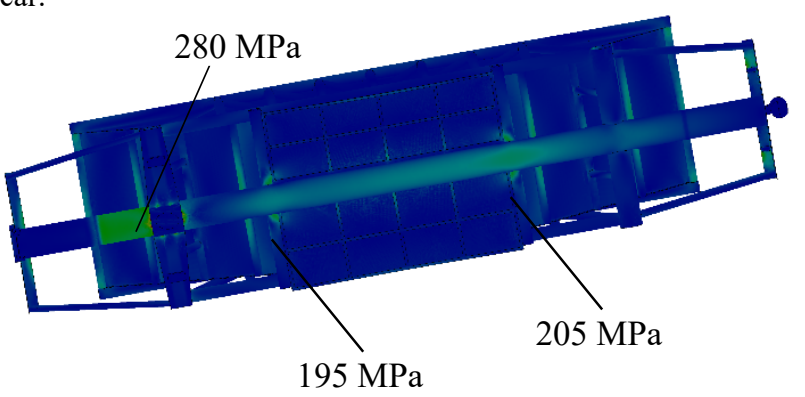

Fig. 9. The stressed state of the section of an articulated hopper car (bottom view).

The distribution of the maximum equivalent stresses along the center sill of the section of the hopper car is given in Fig. 10.

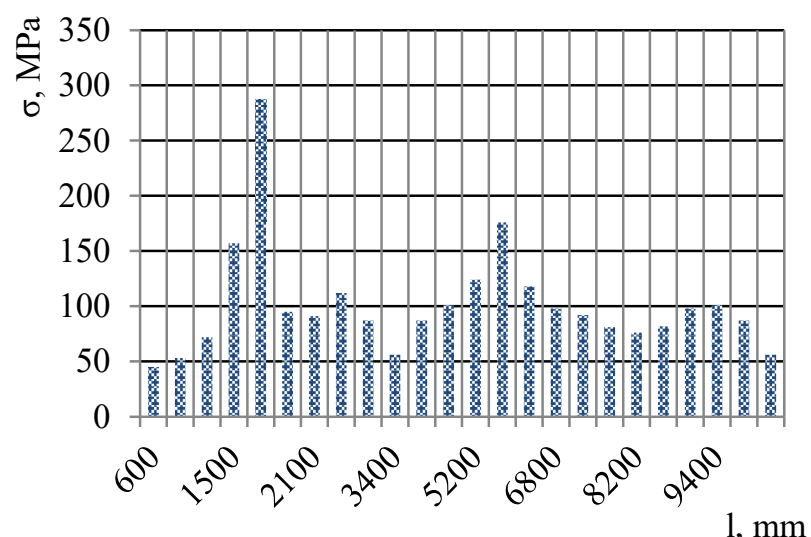

Fig. 10. The distribution of stresses along the bolster beam of a hopper car section.

And the maximum equivalent stresses emerged in the zone of interaction between the center sill and the bolster beam and were about $280 \mathrm{MPa}$, i.e. they did not exceed the admissible values $[10,11,25]$.

The maximum displacements were $5.6 \mathrm{~mm}$ (Fig. 11, 12); they were concentrated in the discharge hoppers. The maximum deformations were $5.810^{-5}$ (Fig. 13, 14).

The temperature impact of the car body was not calculated as the lining sheets of the walls and hoppers were not changed.

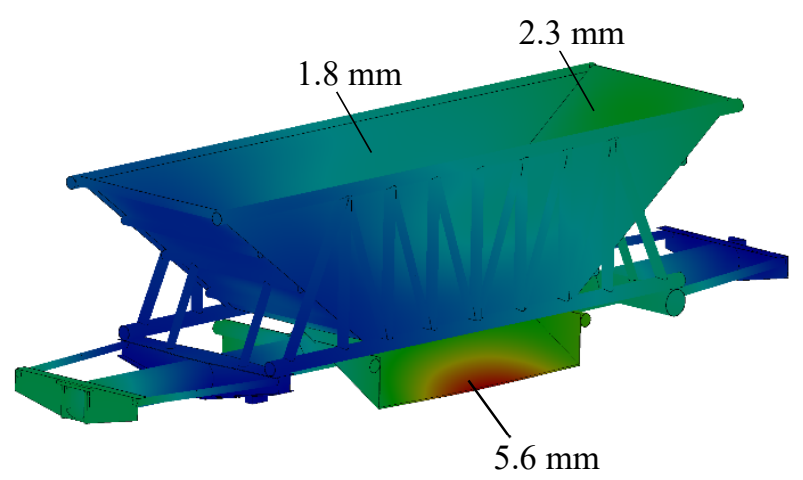

Fig. 11. The displacements in the section units of an articulated hopper car.

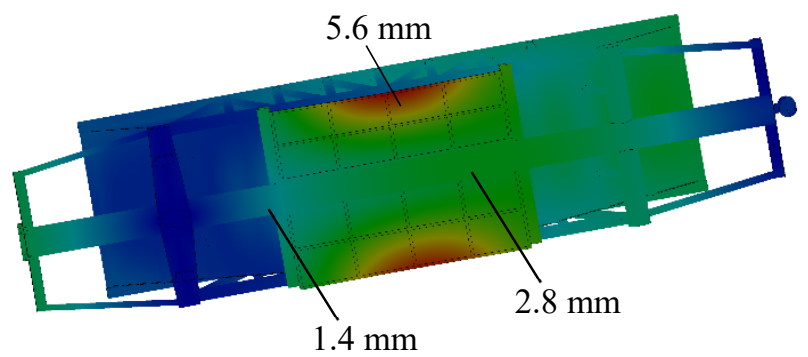

Fig. 12. The displacements in the section units of an articulated hopper car (bottom view).

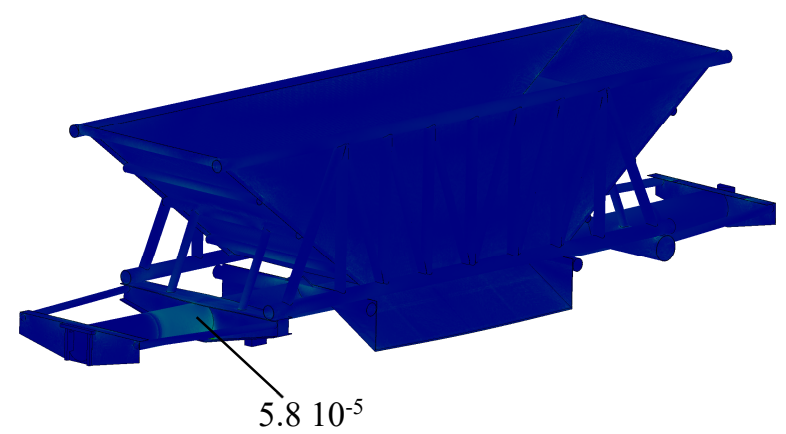

Fig. 13. The deformations in the section units of an articulated hopper car.

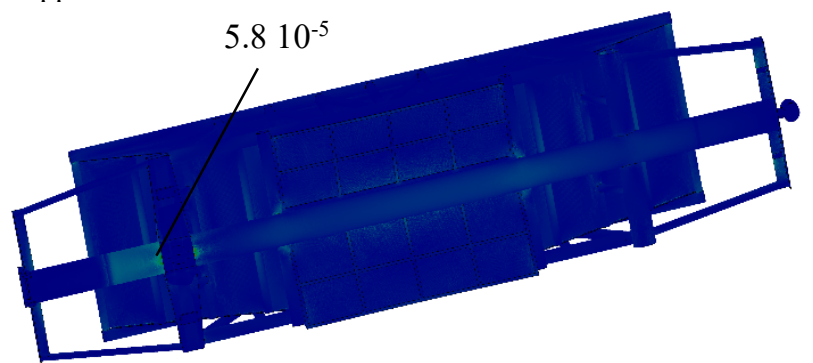

Fig. 14. The deformations in the section units of an articulated hopper car (bottom view).

Besides, the authors conducted a modal analysis of the carrying structure of a hopper car [26, 27] and defined the critical frequencies of oscillations (Table 2).

The results obtained made it possible to conclude that values of the critical frequencies of oscillations were within the admissible range.

Besides, the study presents the calculation of a design service life of a railcar [28-30] 


$$
T_{n}=\frac{\left(\sigma_{-L L} /[n]\right)^{m} \cdot N_{0}}{B \cdot f_{e} \cdot \sigma_{a}^{m}}
$$

where $\sigma_{-1 L}$ - the average value of the endurance limit, MPa; $n$ - the admissible coefficient of the strength factor; $m$ - the exponent of the fatigue curve; $N_{0}$ - the testing base; $B$ - the coefficient indicating a period of continuous run of the object in seconds $f_{e}$ - the efficient frequency of dynamic stresses, $\mathrm{Hz} ; \sigma_{a}$ - the amplitude of equivalent dynamic stresses, MPa.

Table 2. The numerical values of the critical frequencies of oscillations for the carrying structure of an articulated hopper car.

\begin{tabular}{|c|c|c|}
\hline Type of oscillations & Frequency, Hz & Period, from \\
\hline 1 & 10.434 & 0.096 \\
\hline 2 & 12.378 & 0.081 \\
\hline 3 & 13.076 & 0.076 \\
\hline 4 & 15.67 & 0.064 \\
\hline 5 & 17.572 & 0.057 \\
\hline 6 & 18.238 & 0.055 \\
\hline 7 & 21.125 & 0.047 \\
\hline 8 & 27.431 & 0.036 \\
\hline 9 & 27.978 & 0.036 \\
\hline 10 & 28.315 & 0.035 \\
\hline
\end{tabular}

The coefficient characterizing a period of continuous run of the object was determined as follows

$$
B=\frac{365 \cdot 10^{3} \cdot L_{C}}{\vartheta_{a v}(1+0.34)}
$$

where $L_{c}$ - the average daily car run, $\mathrm{km} ; \vartheta_{a v}$ - the average value of the car speed, $\mathrm{m} / \mathrm{sec} ; 0.34$ - the empty run coefficient.

The efficient frequency of dynamic stresses was defined as follows

$$
f_{e}=\frac{1,1}{2 \pi} \sqrt{\frac{g}{f_{s t}}}
$$

where $f_{s t}$ - the static deflection of a spring group, $\mathrm{mm}$.

The following input parameters were taken in the research: the average endurance limit was defined as $0.5 \sigma_{b}$ of the material (Steel grade 09G2C) and accounted for $245 \mathrm{MPa}$; the testing base was $10^{7}$ cycles (recommended for steel); the period of continuous run of the object was $6,514.37 \mathrm{sec}$; the efficient frequency of dynamic stresses considered the spring suspension parameters of a 18-100 bogie and accounted for $2.7 \mathrm{~Hz}$; the admissible strength factor was taken equal to 2; the fatigue curve exponent for a welded structure equaled to 4 ; and the amplitude of equivalent dynamic stresses was $67.3 \mathrm{MPa}$.

On the basis of the calculation it was established that a design service life of the carrying structure of an articulated car is more than 32 years.

\section{Conclusions}

The following conclusions were drawn from the research:
1. The flash-concept of an articulated hopper car for transporting hot pellets and agglomerate was created. A characteristic of the car is the use of circular pipes as the carrying elements of the body. The engineering solution made it possible to decrease the tare weight of the carrying structure of a hopper car in comparison with that of a prototype (Model 20-9749) by $5 \%$.

2. The dynamic loading of a hopper car for transporting hot pellets and agglomerate was determined. It was determined, that the maximum acceleration on a first section (from the side where the longitudinal force was applied) accounted for $31.4 \mathrm{~m} / \mathrm{sec}^{2}$, and on a second section $-32.3 \mathrm{~m} / \mathrm{sec}^{2}$.

3 . The strength values for an articulated hopper car intended for transporting hot pellets and agglomerate were defined.

The maximum equivalent stresses emerging in the carrying structure of an articulated hopper car section were about $280 \mathrm{MPa}$, i.e. they did not exceed the admissible values. The maximum displacements accounted for $5.6 \mathrm{~mm}$ and were concentrated in the discharge hoppers. The maximum deformations were $5.8 \cdot 10^{-5}$

The results of the research will promote designing modern hopper cars for transporting hot pellets and agglomerate, thus increasing the rail transportation efficiency.

The research was conducted within the taxpayer-funded research "Innovative approaches in designing resource-saving car structures with consideration of refined dynamic loading and functional-adaptive flash-concepts".

\section{References}

1. S. Dovhaniuk, V. Kalashnyk, A., Reidemeister, O. Shykunov, Investigation of possibility of hopper cars unloading on the car dumper VRS-134M. MATEC Web of Conferences 294, 06003 (2019)

2. V.I. Senko, A.V. Pigunov, P.M. Afanaskov, S.V. Shestakov, Improvements in the body structure of a hopper car for cement transportation. Bulletin of the GSTU named after P.O. Sukhogo 2, 3-10 (2017)

3. E.V. Afanas'ev, N.A. Bityuczkij, L.V. Czyganskaya, E.A. Ispolova, I.O. Filippova, Renewal of the hopper car fleet for black carbon transportation. News of PSUPE 1, 37-50 (2019)

4. Tsunami Gate wagon to make a splash at Railway Interchange (Railway gazette, 2019), https://www.railwaygazette.com. Accessed 11 Sept 2019

5. O. Fomin, J. Gerlici, A. Lovskaya, K. Kravchenko, P. Prokopenko, A. Fomina, V. Hauser, Research of the strength of the bearing structure of the flat wagon body from round pipes during transportation on the railway ferry. MATEC Web of Conferences 235, (2018)

6. Y.Q. Yuan, Q. Li, K. Ran, Analysis of C80B Wagons Load-Stress Transfer Relation. Applied Mechanics and Materials 148-149, 331-335 (2012) 
7. S.C. Yoon et al., Evaluation of Structural Strength in Body Structure of Freight Car. Key Engineering Materials 417-418, 181-184 (2010)

8. M. Płaczek, A. Wróbel, A. Buchacz, A concept of technology for freight wagons modernization. IOP Conference Series: Materials Science and Engineering 161, 012107 (2016)

9. RPC UWC is presenting the latest products at the International Fair of Railway Equipment and Technologies EXPO (2016), https://www.uniwagon.com. Accessed 23 Aug 2016

10. Freight wagons. General requirements for designing new and improved wagons (non-self-propelled) for a 1520mm gauge. DSTU 7598 (Kyiv, 2015)

11. Freight wagons. Requirements for strength and dynamic qualities. GOST 33211 (Standartinform, Moscow, 2016)

12. D. Kiryanov, Mathcad 15/Mathcad Prime 1.0 (BHV, St. Petersburg, 2012)

13. D. Kiryanov, Tutorial MATHCAD 11: Special directory (BHV, St. Petersburg, 2014)

14. A.V. Kondratiev, V.E. Gaidachuk, M.E. Kharchenko, Relationships between the ultimate strengths of polymer composites in static bending, compression, and tension. Mechanics of Composite Materials 52(2), 259-266 (2019)

15. P. Kucera, V. Pistek, Testing of the mechatronic robotic system of the differential lock control on a truck. International Journal of Advanced Robotic Systems 14(5) (2017)

16. V. Pistek, L. Klimes, T. Mauder, P. Kucera, Optimal design of structure in rheological models: An automotive application to dampers with high viscosity silicone fluids. Journal of Vibroengineering 19(6), 4459-4470 (2017)

17. M. Gorbunov, J. Gerlici, S. Kara, O. Nozhenko, G. Chernyak, K. Kravchenko, T. Lack, New principle schemes of freight cars bogies. Manufacturing Technology 18(2), 233-238 (2018)

18. S.D. Iwnicki, S. Stichel, A. Orlova, M. Hecht, Dynamics of railway freight vehicles. Vehicle System Dynamics 53, 995-1033 (2015)

19. J. Zamecnik, J. Jagelcak, Evaluation of wagon impact tests by various measuring equipment and influence of impacts on cargo stability. Communications 4, 2127 (2015)

20. G. Vatulia, A. Falendysh, Y. Orel, M. Pavliuchenkov, Structural Improvements in a Tank Wagon with Modern Software Packages. Procedia Engineering 187, 301-307 (2017)

21. P. Seshu, Finite Element Analysis (PHI Learning Private Limited, 2012)

22. Zhu Bofang, The finite element metod: Fundamentals and Applications in Civil, Hydraulic, Mechanical and Aeronautical engeneering (China Institute of water resources and gidropower research, 2018)
23. A. Reyes, Beginners guide to SolidWorks 2018 (SDC Publications, 2017)

24. P. Kurowski, Engineering Analysis with SOLIDWORKS Simulation 2010 (Schroff Development Corporation, 2010)

25. Railway applications - Structural requirements of railway vehicle bodies. Part 2: Freight wagons. EN 12663-2 (BSI, Bulgaria, 2010)

26. P. Kurowski, Engineering Analysis with SOLIDWORKS Simulation 2019 (Schroff Development Corporation, 2019)

27. M. Weber, G. Verma, SolidWorks Simulation 2015 Black Book II Edition (CreateSpace Independent Publishing Platform, 2015)

28. O. Fomin, A. Lovska, V. Masliyev, A. Tsymbaliuk, O. Burlutski, Determining strength indicators for the bearing structure of a covered wagon's body made from round pipes when transported by a railroad ferry. Eastern-European Journal of Enterprise Technologies 1/7(97), 33-40 (2019)

29. D.Ya. Antipin, D.Yu. Racin, S.G. Shorokhov, Justification of a Rational Design of the Pivot Center of the Open-top Wagon Frame by means of Computer Simulation. Procedia Engineering 150, 150-154 (2016)

30. C.P. Shukla, P.K. Bharti, Study and Analysis of Doors of BCNHL Wagons. International Journal of Engineering Research \& Technology 4, 1195-1200 (2015) 